\title{
Two case studies of severe storms in the Mediterranean using AMSU
}

\author{
B. M. Funatsu ${ }^{1}$, C. Claud ${ }^{1}$, and J.-P. Chaboureau ${ }^{2}$ \\ ${ }^{1}$ Laboratoire de Meteorologie Dynamique/IPSL, Ecole Polytechnique, 91128 Palaiseau CEDEX, France \\ ${ }^{2}$ Laboratoire d'Aérologie, Observatoire Midi-Pyrénées, 14 avenue Belin, 31400 Toulouse, France
}

Received: 6 March 2007 - Revised: 9 May 2007 - Accepted: 18 June 2007 - Published: 27 June 2007

\begin{abstract}
Mediterranean storms and their associated upper level features are diagnosed here using Advanced Microwave Sounding Unit (AMSU) observations. AMSU-A channel 8 is used to identify upper-level intrusions of stratospheric air, which are often present upstream of heavy precipitating areas, while a combination of AMSU-B channels 3 and 5 is chosen to discriminate moderate to heavily precipitating areas. This precipitation detection method provides results that are in good agreement with TRMM rainfall product and independent ground-based precipitation data. These tools allow us to follow the concomitant evolution of two severe rainfall events in the Mediterranean region and associated upperlevel features.
\end{abstract}

\section{Introduction}

The Mediterranean region is an area of frequent cyclonic activity and presents a complex distribution of this activity due to its intricate orography and latent heat supply. The frequency and intensity of the cyclonic activity however is largely controlled by synoptic-scale perturbations from the midlatitudes such as upper-level troughs and tropopause foldings (e.g. Lionello et al., 2006). A number of climatological studies on Mediterranean lows have been conducted based on reanalysis (e.g. Alpert et al., 1990; Trigo et al., 1999), and satellite (Chaboureau and Claud, 2006) data. These climatological studies, among others, have shown that Mediterranean lows are short-lived compared to those in the midlatitudes, and have typically sub-synoptic scale. They also found intra-seasonal variability in the geographical occurrence and typology of cyclones relative to the associated upper level conditions. Here we propose to explore the direct use (without using inversion algorithms) of the Advanced

Correspondence to: B. M. Funatsu

(funatsu@1md.polytechnique.fr)
Microwave Sounding Unit (AMSU) satellite observations to detect precipitating areas and to identify whether they are associated to upper-level structures. The improved vertical and horizontal resolutions of AMSU compared to TOVS makes AMSU data attractive to study Mediterranean systems. We are particularly interested in the relationship between the characteristics of upper-level structures and precipitation. A further step is to form a climatology of such precipitating systems in the Mediterranean region.

We investigate the potential of AMSU by focusing on selected case studies that are pertinent to the French project CYPRIM (CYclogenése et PRécipitation Intenses en région Méditerranée) and to MEDEX (MEDiterranean EXperiment) project. These cases are spatially distributed so that both western and eastern Mediterranean are covered. In addition, we use data for the entire month of November 2001, covering the whole of the Mediterranean basin, so that results may be suitable for the entire region. The selected cases are: 1 . Algiers [9-10 November 2001] (Tripoli et al., 2005; Söhne et al., 2006); 2. Israel [3-5 December 2001](Krichak et al., 2004); 3. Nîmes-Marseille Storm [8-9 September 2002] (Delrieu et al., 2005); 4. Antalya [5-6 December 2002] (Kotroni et al., 2006); 5. Rhône-Herault Storm [1-3 December 2003] and 6. Herault-Nîmes storm [5-9 September 2005]. All these events produced strong rainfall and severe floods, causing disruption of business, communication and transportation, as well as evacuation of homes in severely affected areas. In this paper we will mainly concentrate on cases 2 and 3 .

\section{Data}

AMSU is a cross-scanning microwave instrument which consists of two modules: AMSU-A which has channels in the molecular Oxygen frequencies $(50-58 \mathrm{GHz})$, mainly designed for atmospheric temperature profile retrieval, and

Published by Copernicus Publications on behalf of the European Geosciences Union. 
(a)



(c)

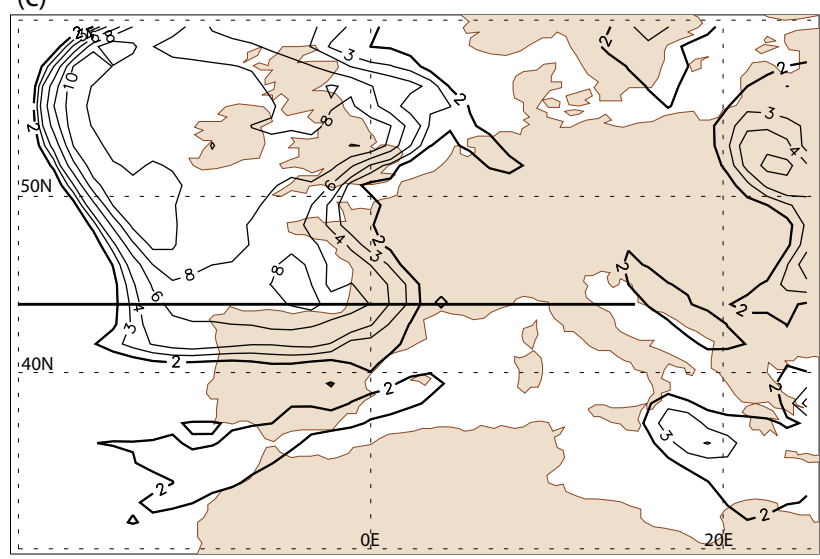

(b)

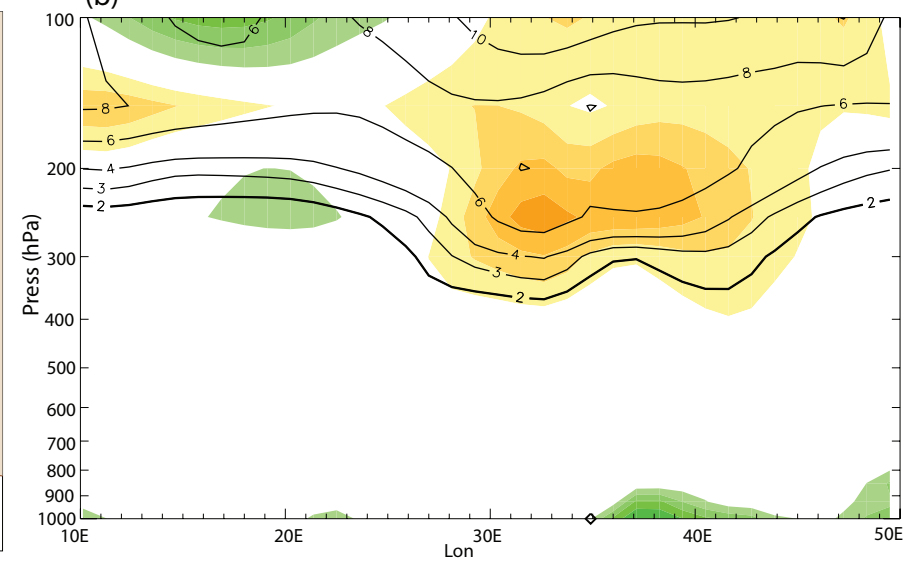

(d)



Fig. 1. Left column: Potential vorticity at $250 \mathrm{hPa}$ (PVU). Right column: cross section of PV (solid) and PV anomaly relative to a monthly mean (shaded). Diamond mark at (a), (b) 12:00 UTC 4 December 2001, Tel Aviv (32.1 ${ }^{\circ}$ 34.9 E) (c), (d) 00:00 UTC 9 September 2002, near Nîmes-Marseille $\left(44^{\circ} \mathrm{N} 4^{\circ} \mathrm{E}\right)$. Thich dark lines in (a), (c) indicate position of cross section for (b), (d), respectively.

AMSU-B which has three channels centered at $183 \mathrm{GHz}$ (water vapor absorption line), designed for optimal moisture retrieval. Furthermore, both modules have window channels, that are not used in this study. The swath width of both AMSU-A and AMSU-B is of approximately $2300 \mathrm{~km}$; the near nadir instantaneous field of view (FOV) of AMSUA is $48 \mathrm{~km}$ while AMSU-B has a near nadir resolution of $16 \mathrm{~km}$. Further details on the instrument can be found in the NOAA's KLM User's Guide available online at http: $/ /$ www2.ncdc.noaa.gov/docs $/ \mathrm{klm} /$. Weighting functions for AMSU-A are shown in e.g., Goldberg et al. (2001).

AMSU has been collecting data onboard NOAA-15, 16 and 17 polar-orbiting satellites starting in 1998, 2000 and 2002, respectively. In this study we use data from NOAA16 and 17 only, mainly because AMSU-B data from these two satellites have small scan asymmetries, comparable to the instrument noise, while NOAA-15 AMSU-B presents large asymmetries (Buehler et al., 2005). NOAA-15 and 16 AMSU-A data also present scan asymmetries, but the effect is mostly significant in the window channels $(23.8,31.4,50.3$ and $89 \mathrm{GHz}$ ), while for the remaining channels this effect is attenuated by the presence of the atmosphere (Weng et al., 2003).

One important point is that AMSU-A data must be corrected for the limb effect, which arises from the fact that the satellite scans a thicker layer in the atmosphere as the field of view departs from the nadir position, thus yielding an artificial cooling/warming of the brightness temperature (BT) for tropospheric/stratospheric channels at larger field of view. Identification of coherent structure and superposition of consecutive orbits is therefore complicated. Here we adjust AMSU-A BTs using coefficients derived from the Radiative Transfer for TOVS (RTTOV) code version 8.5 (Saunders et al., 2005), and based on the case studies listed in Sect. 1. Latitude and time dependency as well as the impact of landsea contrast were taken into account in the analysis and correction. The correction procedure is described in detail in Funatsu et al. (2007).

In order to identify coherent structures in the AMSU-A images we compare them with ERA-40 reanalysis potential 
(a)

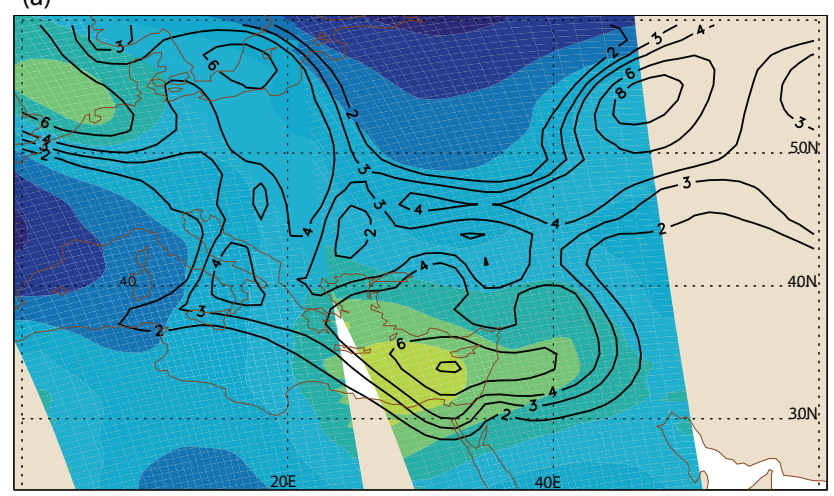

(c)
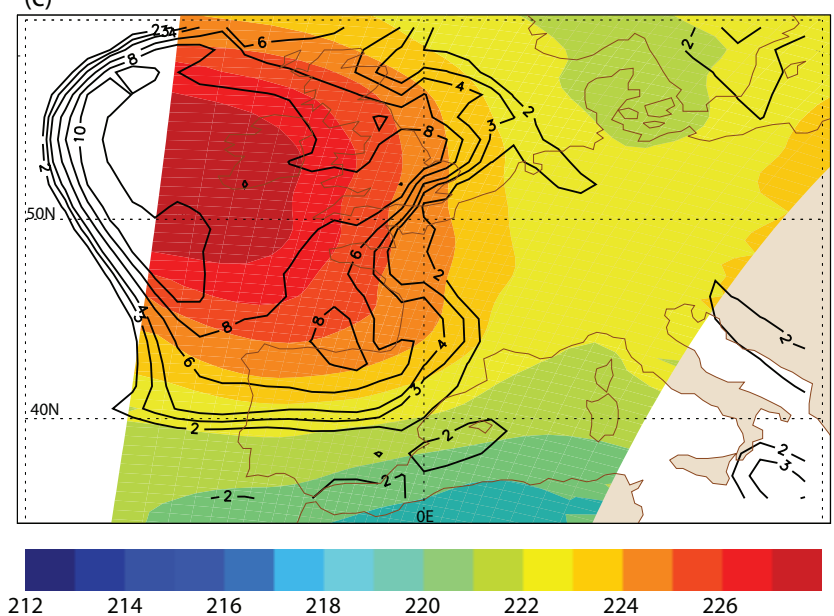

(b)

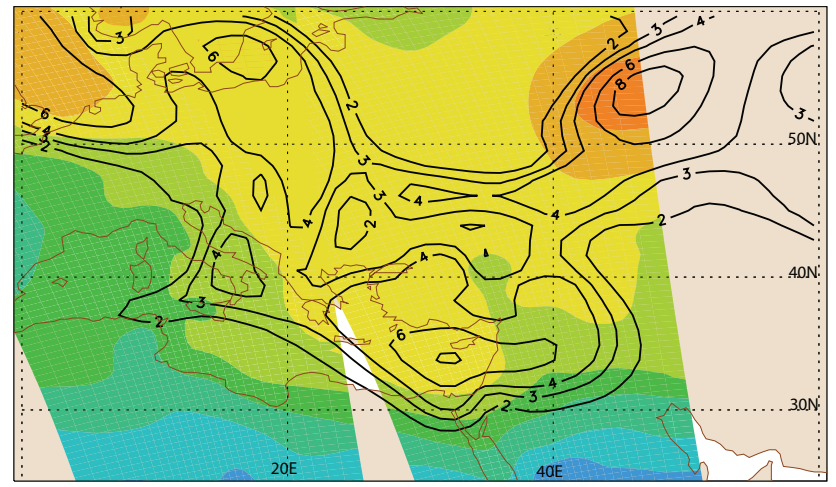

(d)

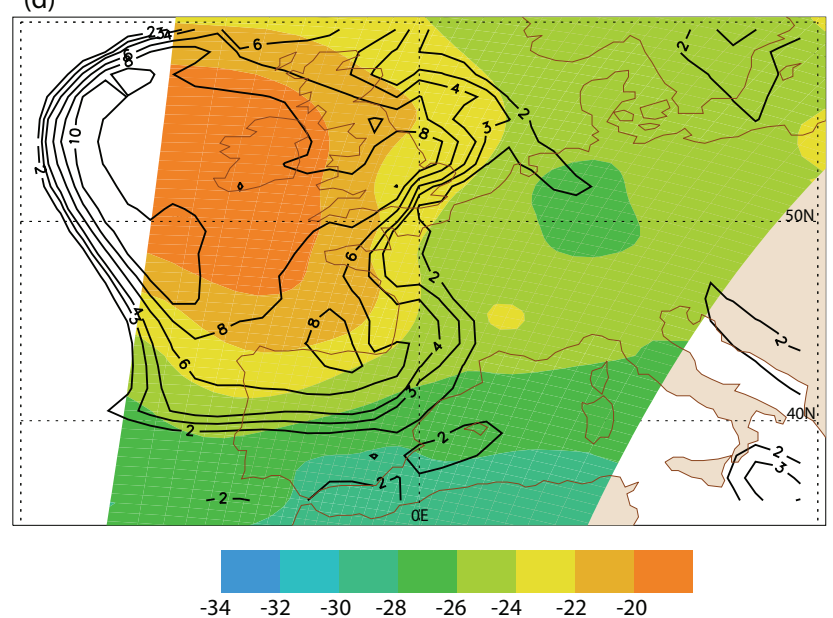

Fig. 2. Limb-corrected AMSU-A channel 8 (left) and AMSU-A channel 7 minus 5 (right), for (a), (b) 09:00-11:00 UTC 4 December 2001, and (c), (d) 02:00 UTC 9 September 2002

vorticity (PV) fields. For rain detection, we use AMSU$\mathrm{B}$ channels 3 to 5 , and for validation, the Tropical Rainfall Measuring Mission (TRMM) 3B42 3-hourly accumulated precipitation product. Additional precipitation measurements were used from both Météo-France Séries Quotidiennes de Référence (SQR) database (Moisselin et al., 2002) and radar-derived and rain gauge network data from the Cévennes-Vivarais Mediterranean Hydrometeorological Observatory (OHM-CV; Delrieu et al., 2005).

\section{Identification of upper level thermal disturbances us- ing AMSU-A}

Figure 1 shows $\mathrm{PV}$ at $250 \mathrm{hPa}$ for one day of cases 2 (Israel) and 3 (Nîmes-Marseille), as well as the cross section of $\mathrm{PV}$ and PV anomaly relative to a one-month mean (i.e., December 2001 and September 2002, respectively). PV anomalies are shown here to emphasize the vertical extent and "strength" of the intrusion. Both cases have in common the presence of an upper level PV "trough", with horizontal and vertical intrusions, and the same is observed for the other case studies (not shown). The cross-sections show that the 2 PVU contour reaches around $350 \mathrm{hPa}$ for case 2 (Fig. 1b) and around $400 \mathrm{hPa}$ for case 3 (Fig. 1d). These stratospheric intrusions have a corresponding anomaly of $+1 \mathrm{PVU}$ or higher, with the strongest positive PV anomaly concentrated around $250 \mathrm{hPa}$. Because of their stratospheric origin, the corresponding thermal signal of an intrusion is a warm anomaly, i.e., increased temperature. AMSU-A channels 7 to 9 have weighting functions peaking in the upper troposphere/lower stratosphere (see, e.g., Fig. 7 of Goldberg et al. (2001)), and the effect of precipitation is reduced or nonexistent, making them suitable candidates to demonstrate the upper tropospheric warming due to a PV intrusion. A first choice is to consider channel 8 (hereafter, A8) since its weighting function maximizes around $200 \mathrm{hPa}$, in the vicinity of the tropopause. An alternative option is to examine the difference of channels, e.g., channel 7 minus 5 (hereafter A7m5). This way, the lower troposphere signal of channel 7 is removed, with the further advantage of mitigating the impact of sea-land contrast in the limb-correction. 
Figure 2 shows limb-corrected A8 and A7m5, and $250 \mathrm{hPa}$ $\mathrm{PV}$ at the nearest hour, for cases 2 and 3 . In general, both $\mathrm{A} 8$ and $\mathrm{A} 7 \mathrm{~m} 5$ are able to detect a warm core in the vicinity of, or nearly coincident with, high PV. Careful examination of these figures and their sequences (not shown) shows that channel 8 performs better in identifying the upper level PV and its strength, than do the difference channels, 7 minus 5. This fact is evident for example in case 2: A warm A8 BT of $221 \mathrm{~K}$ can be found near the zonally elongated PV region with core values greater than 6PVU, over the eastern Mediterranean Sea (Fig. 2a). In contrast, no particular counterpart is observed in A7m5 (Fig. 2b). This observation was corroborated by examining all case studies, from which the results indicate that channel 8 is more suitable to detect upper level features (independent of the extent of their vertical penetration), while $\mathrm{A} 7 \mathrm{~m} 5$ only displays a warm anomaly in cases of deep intrusions.

A question that remains open is what is the most suitable threshold of BT that captures PV greater than $2 \mathrm{PVU}$ at $250 \mathrm{hPa}$. The determination of such a threshold is desired to objectively discriminate areas of southward mass intrusions that have potential to produce severe weather in the Mediterranean. A8 BT larger than $221 \mathrm{~K}$ roughly coincides with regions where $\mathrm{PV}$ is larger than $4 \mathrm{PVU}$ for example in case 2. However, when the stratospheric intrusion has very large values of $\mathrm{PV}$, the area where A8 $\mathrm{BT} \geq 221 \mathrm{~K}$ may cover a broader region than the intrusion itself. This effect is more pronounced the larger the $\mathrm{PV}$ values. One such example is seen for case 3, in Fig. 2c: A8 BT $\geq 223 \mathrm{~K}$ delineates the area of intrusion, while the area covered by $\mathrm{A} 8 \mathrm{BT} \geq 221 \mathrm{~K}$ encompasses but does not define the PV trough. This suggests that the threshold of A8 BT $\geq 221 \mathrm{~K}$ can be taken as a "necessary" condition to detect significant PV anomalies, but further analysis is still needed to determine an absolute threshold.

\section{Detection of precipitation using AMSU-B}

We focused on AMSU-B channels 3 to 5 data for detection of precipitating systems. We chose to explore these channels because they are less affected by the underlying surface (Deeter and Vivekanandan, 2005), while being sensitive to frozen hydrometeors and therefore useful to detect cold clouds (Greenwald and Christopher, 2002; Hong et al., 2005). We concentrated on the case studies listed in Sect. 1 and the entire month of November 2001, with the aim of determining two thresholds using channels 3 to 5: One that is able to identify precipitating systems in general, and another that will indicate areas with deep convective clouds.

For the remaining of the text, the term "TRMM rain" will refer to TRMM accumulated rain in $3 \mathrm{~h}$ (3B42 product). The proposed rationale to determine a threshold to identify precipitating systems (in general) was based on constructions of two histograms for each pair of differences B4m5 (i.e., the difference between channels 4 and 5 of AMSU-B), $\mathrm{B} 3 \mathrm{~m} 5$ and $\mathrm{B} 3 \mathrm{~m} 4$ : one cumulative $\mathrm{BT}$ distribution whenever TRMM rain was equal or larger than $10 \mathrm{~mm}$, and the other a cumulative BT distribution for TRMM rain equal to 0 . The optimal AMSU BT value was selected as the interception of the two cumulative curves. The areas of comparison were chosen such that areas covered by snow were not included (for example, the Alps, the Carpathians mountains and the eastern coast of Croatia). Results from this analysis indicated that the combination B3m5 is the most robust, showing a small variance compared to its mean value of $-8 \mathrm{~K}$. Therefore, in a statistical sense a value of $\mathrm{B} 3 \mathrm{~m} 5 \geq-8 \mathrm{~K}$ will have more chance of detecting precipitation that may accumulate at least $10 \mathrm{~mm}$ in $3 \mathrm{~h}$ than yielding a false positive (once snow-covered areas are discarded).

The second threshold of interest was one to discriminate convective systems. For this purpose we considered the tropical deep convective threshold (DCT; Hong et al., 2005) which requires that deep convective clouds satisfy simultaneously the condition $\mathrm{B} 3 \mathrm{~m} 4, \mathrm{~B} 3 \mathrm{~m} 5$ and $\mathrm{B} 4 \mathrm{~m} 5$ greater or equal to zero. In order to examine whether the tropical DCT is applicable to detect heavily precipitating systems in the Mediterranean, we performed a search of all gridpoints where DCT condition is satisfied and compared to the TRMM rain at the same gridpoints in order to obtain an estimate of the precipitation levels that this condition can detect. Results of this analysis indicated that in nearly $80 \%$ of the cases whenever the DCT criterion is reached there is accumulated precipitation. In nearly $50 \%$ of the cases there is $3-\mathrm{h}$ accumulated precipitation above $20 \mathrm{~mm}$. Despite the inherent differences in the nature of the accumulated precipitation as compared to instantaneous observations, which prevents us from firmly determine the validity of these precipitation thresholds, we claim that the above results are encouraging for its application in the Mediterranean. This analysis was repeated against convective indexes proposed by Qiu et al. (2005), which are also based on AMSU-B channels 3 to 5, and defined for areas outside the tropical region. We found that the criteria of Hong et al. (2005) performs slightly better than the index of Qiu et al. (2005) to detect precipitating areas that yield accumulated values above $20 \mathrm{~mm}$, and therefore we propose to use the former to detect areas of deep convection in the Mediterranean. Further comparison of B3m5 $\geq-8 \mathrm{~K}$ and DCT with independent ground data is shown in the next section.

\section{Application to two severe storm events}

\subsection{Gard Region (France)}

On 8-9 September 2002, a mesoscale convective system passed over Gard Region (south France) causing strong rainfall and flash floods. Rain amounts greater than $200 \mathrm{~mm}$ were reported between 08:00-22:00 UTC 8 September near 




(b)

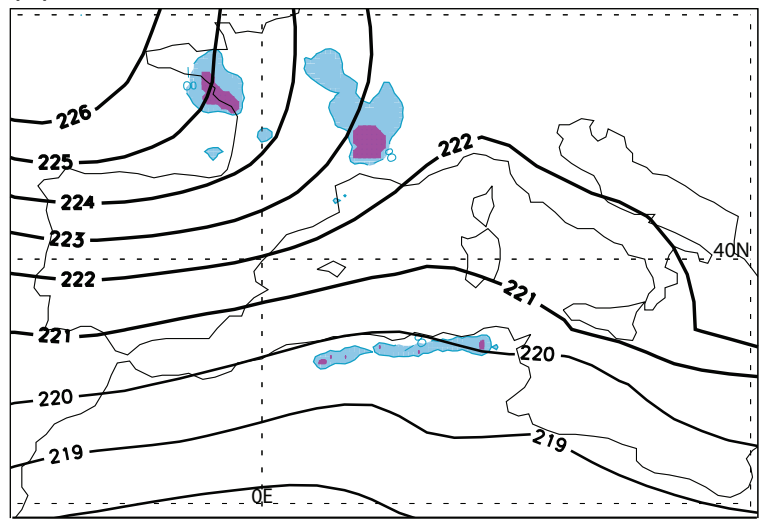

(c)

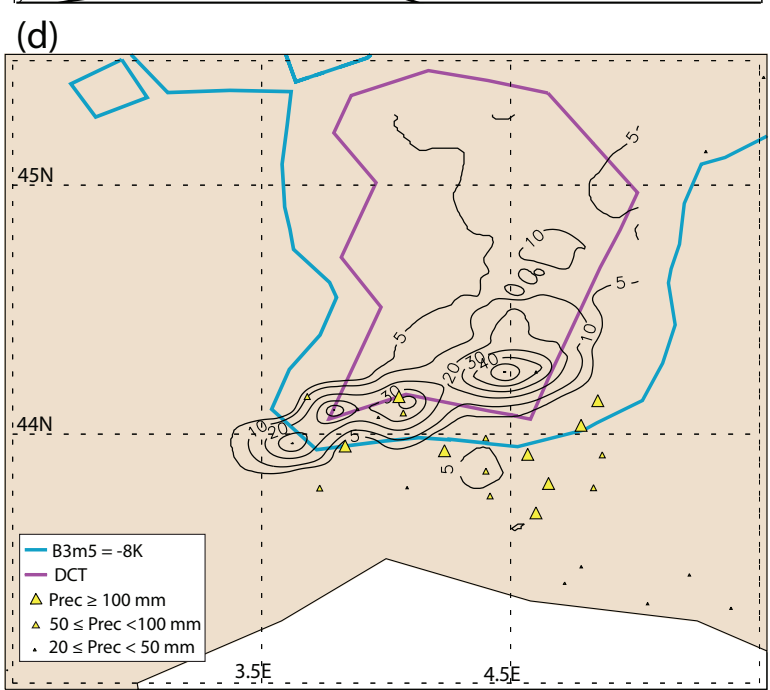

Fig. 3. (a) Meteosat Infrared image at 23:30 UTC 8 September 2002; (b) AMSU-A 8 (black, $\geq 221 \mathrm{~K}$ thick dark), AMSU-B3m5 $\geq-8 \mathrm{~K}$ (blue) and DCT (purple), in the area delimited by red square in (a); (c) AMSU-B3m5=-8 K (blue), DCT (purple), SQR accumulated rainfall data (triangles) between 05:00 UTC 8 September and 05:00 UTC 9 September 2002, and radar derived precipitation intensity (mm/h) at 02:30 UTC 9 September; and (d) as in (c) but black contours for rain gauge network 1-h accumulated precipitation (mm) between 02:0003:00 UTC 9 September, from the Cévennes-Vivarais Mediterranean Hydrometeorological Observatory.

the city of Nîmes, and the total accumulated rainfall for the event reached between $600-700 \mathrm{~mm}$ in the region. A synoptic and hydrological study of this storm is detailed in Delrieu et al. (2005). Figure 3a shows the Meteosat infrared image at 23:30 UTC of 8 September and Fig. 3b shows A8, B3m5 and DCT for the closest orbit to this hour (02:00 UTC 9 September 2002). There is a qualitatively good correspondence between the areas with bright IR signal (which indicated position of thick, cold clouds) and the precipitating areas depicted by AMSU-B (Figs. 3a and b). A8 $\gg 221 \mathrm{~K}$ can be seen in the NW corner in Fig. 3b, and this area is coincident with a strong PV intrusion, as shown in Fig. 2c. The sequence of $\mathrm{A} 8, \mathrm{~B} 3 \mathrm{~m} 5$ and $\mathrm{DCT}$ for this event showed a con- vective system at around 00:00 UTC 8 September over the Mediterranean sea, while other precipitating areas developed over Spain at the southern edge of A8 BT ridge, between 00:00-12:00 UTC 8 September. During this period, the convective area over the Mediterranean moved inland, towards Nîmes, and intensified (Fig. 3b). Later on, near 12:00 UTC 9 September, a large precipitating area could still be seen over Nîmes, as the A8 BT ridge got narrower and stronger (not shown).

Figure $3 \mathrm{c}, \mathrm{d}$ show a comparison between $\mathrm{B} 3 \mathrm{~m} 5=-8 \mathrm{~K}$ and DCT with SQR and OHM-CV precipitation data. There is a quite good agreement between the area defined by $\mathrm{B} 3 \mathrm{~m} 5=-8 \mathrm{~K}$ and DCT with the independent SQR and OHM- 
(a)

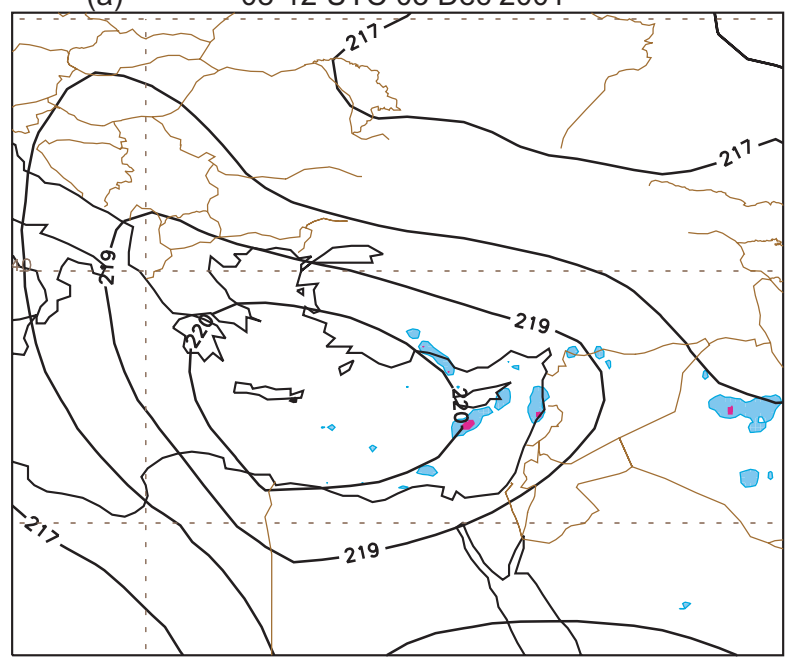

(c)

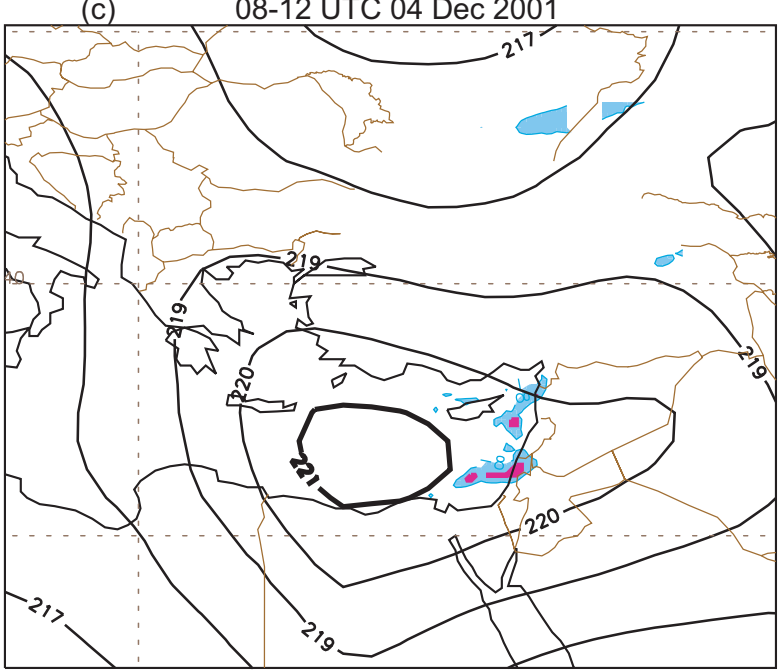

(b) 22-03 UTC 04 Dec 2001

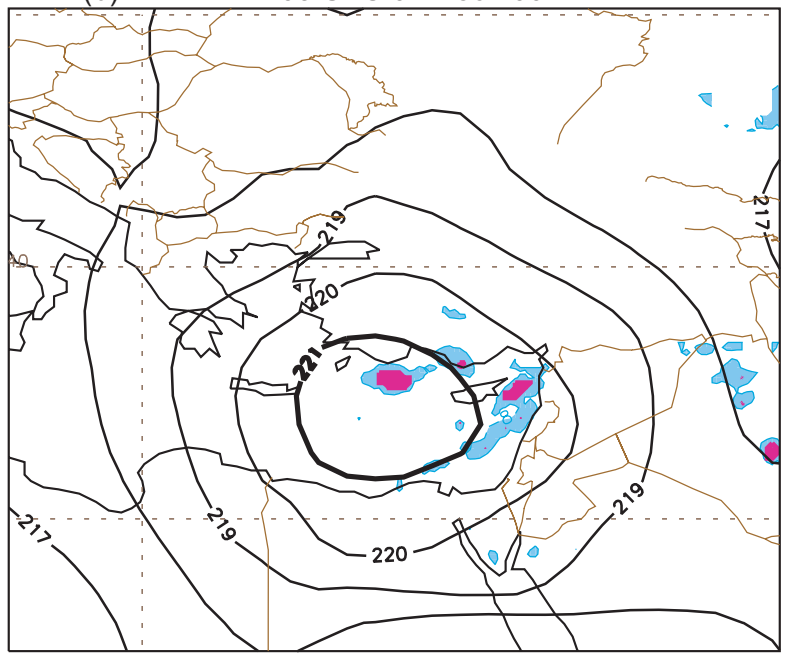

(d)



Fig. 4. A8 (black contours), B3m5 $\geq-8 \mathrm{~K}$ (blue), and DCT (purple) for AMSU orbits between (a) 08:00-12:00 UTC 3 December 2001, (b) 23:00-03:00 UTC 4 December 2001, (c) 08:00-12:00 UTC 4 December 2001, (d) 23:00-03:00 UTC 5 December 2001.

$\mathrm{CV}$ data. $\mathrm{B} 3 \mathrm{~m} 5=-8 \mathrm{~K}$ and $\mathrm{DCT}$ define a region in which there is significant accumulated precipitation in the next hour (OHM-CV) and/or subsequent hours (SQR). Because the AMSU-B measurements and ground stations are completely independent, these results give us additional confidence that these thresholds are suitable for detecting moderate to strong rainfall. Furthermore, this satellite description show that the precipitating areas are downstream of the upper level trough and they intensify as the A8 BT ridge amplifies.

\subsection{Northern Israel}

Torrential rains fell over a narrow coastal region in northern Israel during 4-5 December 2001, with reported accumulated precipitation of up to $200 \mathrm{~mm}$ during 01:00-07:00 UTC 4 December at one station. A description and discussion on the dynamical precursors of this event can be found in
Krichak et al. (2004). Figures $4 \mathrm{a}-\mathrm{d}$ show a time sequence of A8, B3m5 $\geq-8 \mathrm{~K}$ and DCT for 3-5 December 2001. An area of $\mathrm{A} 8>220 \mathrm{~K}$ centered just southeast of Crete is found between 08:00-12:00 UTC 3 December. Areas of precipitation, one of them including a small convective region, are found downstream (Fig. 4a). By the early hours of 4 December, the A8 BT core has intensified, reaching $221 \mathrm{~K}$, and moved eastward, centered at approximately $35^{\circ} \mathrm{N} 28.6^{\circ} \mathrm{E}$. As this core deepened, areas of heavy precipitation developed just off the southern coast of Turkey, and between Cyprus and Lebanon (Fig. 4b). Between 08:00-12:00 UTC 4 December, the upper level feature has moved southward, and so did the areas of intense precipitation (Fig. 4c). In particular, a convective cell can be seen over Northern Israel, extending westward in the Mediterranean Sea. As the center of the high A8 BT core moved southeastward on the 5 December (Fig. 4d), it also elongated in the NE-SW direction. At 
this time, the rainfall areas diminished and weakened. Subsequent images show that the BT core elongates in the N-S direction and moves further south, and rainfall areas decrease altogether (not shown). This depiction shows that A8, B3m5 and DCT are able to diagnose the location and strengh of the upper level trough and concomitant evolution of the precipitating areas. Similary to the previous case these rainfall areas are found mainly downstream of the A8 BT maxima, and its intensity follows the intensity (stronger when A8 ridge amplified) and relative location of the A8 BT core to the surface system (less precipitation when A8 moved southward).

\section{Summary and conclusions}

In this work we demonstrated the potential of AMSU to detect both upper level disturbances that are often precursors of severe weather systems in the mid-latitudes, and its associated precipitation for two heavy rainfall events.

We found that both $\mathrm{A} 8$ and $\mathrm{A} 7 \mathrm{~m} 5$ can detect upper level PV intrusions. However A8 performs better than the combination of channels especially if the intrusion is shallow. Furthermore, higher A8 BT are observed as the maximum PV increases. A necessary (although not sufficient) condition to identify a PV greater than $4 \mathrm{PVU}$ at $250 \mathrm{hPa}$ is that the A8 BT is at least $221 \mathrm{~K}$. When very strong stratospheric intrusions are present, this condition was found not to be effective enough to isolate the PV intrusion. One possible approach would be to use both A8 and A7m5, and we are currently investigating this possibility.

For detection of precipitation, we found that the differences between channels 3 and 5 of AMSU-B gave the most quantitatively consistent result, yielding a threshold of $-8 \mathrm{~K}$ to detect accumulated precipitation of at least $10 \mathrm{~mm} / 3 \mathrm{~h}$. This result was obtained for areas outside the Alps, the Pyrenees and the mountainous regions around the Black Sea, which are problematic due to the high elevation and presence of snow. Therefore, we use the additional information of snow depth from ERA-40 to filter out possible contamination from snow on the ground. We also found that the tropical DCT criteria was able to isolate areas in the Mediterranean basin that produced accumulated rainfall of at least $20 \mathrm{~mm} / 3 \mathrm{~h}$, in approximately $50 \%$ of the cases. Our results were supported with comparison with independent ground data, and shown to be fairly robust.

Finally, we used these channels to depict two heavy rainfall events: 8-9 September 2002 in the Gard region (France), and 4-5 December 2001 in Israel. Upper-level (high-PV) troughs were detected using A8 and precipitating and convective areas using $\mathrm{B} 3 \mathrm{~m} 5$ and DCT. In both cases the intensity and position of the upper level A8 BT relative to the areas of precipitation were found to have an impact on the intensity and extent of the rainfall. A more intense A8 BT core, upstream of the storm, was usually accompanied by intense convection in both cases, suggesting a baroclinic interaction between upper and low level systems.

Diagnostics using AMSU can be used in real time for forecast purposes and for model verification as in, for example, Chaboureau and Pinty (2006) and Söhne et al. (2006). Future work aims at using these channels to establish a climatology of precipitating systems and their typology relative to the upper level situation, in a similar manner to Chaboureau and Claud (2006) for cloud systems.

Acknowledgements. This study is part of and funded by the project CYPRIM (CYclognenèse et PRécipitation Intenses en région Méditerranéenne). We thank Brice Boudevillain (LTHE) for accumulated rainfall and radar data, and Véronique Ducrocq (Météo France) for the SQR data used in this study. The TRMM and Other 3-hourly accumulated rainfall data were acquired using the GES-DISC Interactive Online Visualization ANd aNalysis Infrastructure (Giovanni) as part of the NASA's Goddard Earth Sciences (GES) Data and Information Services Center (DISC).

Edited by: P. Alpert, H. Saaroni, and E. Heifetz

Reviewed by: two anonymous referees

\section{References}

Alpert, P., Neeman, B. U., and Shay-El, Y.: Climatological analysis of Mediterranean cyclones using ECMWF data, Tellus, 42A, 6577, 1990.

Buehler, S. A., Kuvatov, M., and John, V. O.: Scan asymmetries in AMSU-B data, Geophys. Res. Lett., 32, L248110, doi:10.1029/2005GL024747, 2005.

Chaboureau, J.-P. and Claud, C.: Satellite-based climatology of Mediterranean cloud systems and their association with large-scale circulation, J. Geophys. Res., 111, D01102, doi:10.1029/2005JD006460, 2006.

Chaboureau, J.-P. and Pinty, J.-P.: Validation of a cirrus parameterization with Meteosat Second Generation observations, Geophys. Res. Lett., 33, L03815, doi:10.1029/2005GL024725, 2006.

Deeter M. N. and Vivekanandan, J.: AMSU-B observations of mixed-phase clouds over land, J. Appl. Meteorol., 44, 72-85, 2005.

Delrieu G. and co-authors: The catastrophic flash-flood event of 89 September 2002 in the Gard Region, France: A first case study for the Cévennes-Vivarais Mediterranean Hydrometeorological Observatory, J. Hydrometeorol., 6, 34-52, 2005.

Goldberg, M. D., Crosby, D. S., and Whou, L.: The limb adjustment of AMSU-A observations: Methodology and validation, J. Appl. Meteorol., 40, 70-83, 2001.

Greenwald, T. J. and Christopher, S. A.: Effect of cold clouds on satellite measurements near $183 \mathrm{GHz}$, J. Geophys. Res., 107(D13), 4170, doi:10.1029/2000JD000258, 2002.

Funatsu, B. M., Claud, C., and Chaboureau, J.-P.: Potential of Advanced Microwave Sounding Unit to identify precipitating systems and associated upper-level features in the Mediterranean region: Case studies, J. Geophys. Res., doi:10.1029/2006JD008297, in press, 2007.

Hong, G., Heygster, G., Miao, J., and Klaus, K.: Detection of tropical deep convective clouds from AMSU-B vapour 
channels measurements, J. Geophys. Res., 110, D05205, doi:10.1029/2004JD004949, 2005.

Kotroni, V., Lagouvardos, K., Defer, E., Dietrich, S., Porcù, F., Medaglia, C. M., and Demirtas, M.: The Antalya 5 December 2002 storm: Observations and Model Analysis, J. Appl. Meteorol. Climatol., 45, 576-590, 2006.

Krichak, S. O., Alpert, P., and Melina, D.: The role of atmospheric processes associated with Hurricane Olga in the December 2001 floods in Israel, J. Hydrometeorol., 5, 1259-1270, 2004.

Lionello, P. and co-authors: Cyclones in the Mediterranean region: Climatology and effects on the environment, in: Mediterranean Climate Variability, edited by: Lionello, P., Malanotte-Rizzoli, P., and Boscolo R., Elsevier, pp. 325-372, 2006.

Moisselin, H. M., Schneider, M., Canellas, C., and Mestre, O.: Les changements climatiques en France au 20ème siècle: Etude des longues séries homogénéisées de données de température et de précipitations, Météorologie, 38, 45-56, 2002.

Qiu, S., Pellegrino, P., Ferraro, R., and Zhao, L.M.: The improved AMSU rain-rate algorithm and its evaluation for a cool season event in the western United States, Wea. Forecast., 20, 761-774, 2005.
Saunders, R. W., Matricardi, M., Brunel, P., English, S., Bauer, P., O'Keeffe, U., Francis, P., and Rayer, P.: RTTOV-8 science and validation report, technical report, 41 pp., Numer. Weather Predic. Satell. Appl. Facil. Exeter, UK, 2005.

Söhne, N., Chaboureau, J.-P., Argence, S., Lambert, D., and Richard, E.: Objective evaluation of mesoscale simulations of the Algiers 2001 flash flood by the model-to-satellite approach, Adv. Geosci., 7, 247-250, 2006, http://www.adv-geosci.net/7/247/2006/.

Trigo, I. F., Davies, T. D., and Bigg, G. R.: Objective climatology of cyclones in the Mediterranean region, J. Climate, 12, 16851696, 1999.

Tripoli, G. J., Medaglia, C. M., Dietrick, S., Mugnai, A., Panegrossi, G., Pinori, S., and Smith, E. A.: The 9-10 November 2001 Algerian Flood: A numerical study, B. Am. Meteorol. Soc., 86, 1229-1235, 2005.

Weng, F., L. Zhao, Ferraro, R. R., Poe, G., Li, X., and Grody, N. C.: Advanced microwave sounding unit cloud and precipitation algorithms, Radio Sci., 38, 8068, doi:10.1029/2002RS002679, 2003. 